\title{
Lung Surfactant
}

National Cancer Institute

\section{Source}

National Cancer Institute. Lung Surfactant. NCI Thesaurus. Code C13273.

Pulmonary surfactant lines the lung epithelium and lowers surface tension to prevent collapse at end-expiration. Deficiency of pulmonary surfactant results in respiratory distress syndrome (RDS) in premature infants. Lung surfactant is synthesized in alveolar type II cells, stored in lamellar bodies and secreted via exocytosis. 